Malaysian Journal of Social Sciences and Humanities (MJSSH)

Volume 4, Issue 7, November 2019

e-ISSN : 2504-8562

Journal home page:

www.msocialsciences.com

\title{
Kerangka Kaedah Kajian Penyelidikan: Faktor-faktor yang Mempengaruhi Komitmen Prestasi Kerja
}

\author{
Norsyamimi Nordin', Mohammad Mujaheed Hassan ${ }^{1}$ \\ ${ }_{1}^{1}$ Jabatan Sains Kemasyarakatan dan Pembangunan, Fakulti Ekologi Manusia, Universiti Putra Malaysia (UPM) \\ Correspondence: Mohammad Mujaheed Hassan (mujaheed@upm.edu.my)
}

\begin{abstract}
Abstrak
Prestasi kerja dilihat sebagai suatu set tingkah laku yang relevan dengan pencapaian matlamat organisasi atau unit organisasi tempat seseorang itu bekerja. Kerajaan telah menyarankan budaya kerja berasaskan prestasi dengan menggunakan petunjuk-petunjuk prestasi utama atau Key Performance Indicators (KPI) yang diterapkan dalam perkhidmatan awam mahupun swasta bagi meningkatkan kualiti penyampaian perkhidmatan. Sejajar dengan visi, misi dan fungsi agensi, setiap organisasi perlu mengukur prestasi perkhidmatan yang diberikan bagi memastikan semua perkhidmatan berkenaan disampaikan kepada pelanggan dengan baik. Ini secara tidak langsung dapat memberikan gambaran yang jelas mengenai prestasi organisasi secara keseluruhannya. Menyedari akan kepentingan prestasi kerja dalam meningkatkan kecemerlangan sesebuah organisasi, maka kajian ini cuba menghasilkan kerangka kaedah kajian penyelidikan bagi mengkaji faktor komitmen kerja yang mempengaruhi prestasi kerja seseorang pekerja di dalam organisasi. Walaubagaimanapun, kerangka kajian penyelidikan ini hanya memberi penekanan kepada empat faktor komitmen kerja yang mempengaruhi prestasi kerja yang utama sahaja sebagai pemboleh ubah tidak bersandar iaitu faktor penyeliaan, rakan sekerja, pendapatan dan minat. Kajian ini juga akan menjadikan latar belakang seperti jantina, umur dan tempoh pekerjaan sebagai pembolehubah terdahulu yang akan dihubungkaitkan dengan prestasi kerja secara tidak langsung. Kaedah kajian penyelidikan yang digunakan adalah kaedah kuantitif dengan menggunakan borang soal selidik untuk mendapatkan maklumat daripada responden. Kerangka kajian di jangka mampu membantu sesebuah organisai mengenalpasti isu di dalam organisasi dan mengambil tindakan yang sewajarnya bagi meningkatkan prestasi kerja mereka.
\end{abstract}

Kata kunci: faktor komitmen kerja, prestasi kerja, minat, penyeliaan, rakan sekerja, pendapatan

\section{Research Method Framework: Factors Influencing Work Performance Commitment}

\begin{abstract}
Work performance is measured as a set of behaviors that are contribute to the achievement of the goals of the unit or organisation in which a person works. The government has promoted a performancebased work culture using Key Performance Indicators (KPIs) implemented in both public and private services to improve the quality of service delivery. In line with the agency's vision, mission and function, each organization must measure the performance of the services provided to ensure that all of its services are delivered to customers well. This indirectly provides a clear picture of the overall performance of the organization. However, what factors influence the commitment of work performance to an employee within an organization ?. Recognizing the importance of quality work
\end{abstract}


performance in enhancing an organization's excellence, this study attempts to develop a research methodology to study the factors affecting an employee's work commitment and performance within the organization. However, the framework of this research study focuses on only four variables to measure work commitment that influence only the main job performance as independent variables namely supervisory, coworkers, income and interest towards the job. This study will also utilize the respondents' personal information such as gender, age and duration of employment as the primary variables that are considered as indirectly related to their work performance. The research method used was the quantitative method using questionnaires to obtain information from the respondents. It is hoped that this improvised method can help an organization identify issues which can be addressed to improve the employees' work performance.

Keywords: factors of commitment, job performance, interest, supervision, co-worker, income

\section{Pengenalan}

Neol (2009) mendefinisikan prestasi kerja sebagai satu proses dimana pengurus bertanggungjawab memastikan aktiviti dan produktiviti pekerja selari dengan matlamat organisasi. Petunjuk-petunjuk prestasi utama atau Key Performance Indicators (KPI) adalah satu sistem pengukuran yang mudah, berkesan dan membantu organisasi menjelaskan dan mengawal tahap kemajuan sesuatu proses perkhidmatan yang disampaikan kepada pelanggan selaras dengan misi dan visi sesebuah organisasi (Pekeliling Kemajuan Pentadbiran Awam Bilangan 2 Tahun 2005). Prinsip-prinsip KPI ialah meletakkan sasaran, boleh diukur dengan angka, diukur dalam keadaan normal dan selaras dengan misi dan visi organisasi. KPI adalah ukuran spesifik dalam bidang tertentu prestasi organisasi.

Prestasi kerja amat dipengaruhi oleh faktor luaran dan dalaman seseorang pekerja itu sendiri. Oleh itu kajian ini akan menghasilkan kerangka kaedah kajian penyelidikan bagi mengkaji faktor komitmen kerja mempengaruhi prestasi kerja. Kerangka kaedah kajian penyelidikan ini boleh digunakan untuk mengkaji latar belakang umum pekerja seperti jantina, umut dan tempoh perkhidmatan; mengenalpasti faktor dan tahap komitmen kerja yang mempengaruhi prestasi kerja; mengkaji hubungan antara faktor komitmen kerja dengan prestasi kerja; dan mengkaji perbezaan di antara jantina, umur dan tempoh perkhidmatan dengan prestasi kerja.

\section{Sorotan Kajian Lepas}

Siti Barokah Kasran (1999) telah membuat satu kajian penyelidikan terhadap sistem penilaian prestasi kerja dengan tahap prestasi kerja di dua buah organisasi iaitu Dewan Bandaraya Kuching Utara (DBKU) dan Syarikat Telekom Malaysia Sdn. Bhd. yang bertempat di Simpang Tiga, Kuching, Sarawak. Kajian ini melibatkan seramai 76 orang responden daripada DBKU dan 72 orang responden daripada Telekom. Kajian ini melihat tahap persepsi pekerja terhadap sistem penilaian prestasi dan tahap prestasi kerja secara berasingan dengan mengambilkira faktor demografi. Dapatan kajian menunjukkan tiada sebarang hubungan yang signifikan antara semua faktor demografi pekerja di DBKU dan Telekom dengan persepsi mereka terhadap sistem penilaian prestasi dan juga terhadap tahap prestasi kerja mereka, kecuali faktor jantina terhadap sistem penilaian prestasi di Telekom. Hasil kajian juga mendapati bahawa terdapat hubungan yang signifikan antara persepsi pekerja terhadap sistem penilaian prestasi dengan tahap prestasi kerja di DBKU $(\mathrm{r}=0.452, \mathrm{p}<0.452)$ dan Telekom $(\mathrm{r}=0.434, \mathrm{p}<0.01)$ pada tahap sederhana. Kedua-dua perhubungan ini adalah positif pada tahap yang sederhana.

Selain itu, Rambli (2001) telah menjalankan kajian terhadap 143 orang pekerja di industri pembuatan untuk mengenalpasti perkaitan antara kepuasan kerja dengan prestasi kerja. Faktor-faktor kepuasan pekerja terdiri daripada keadaan kerja, gaji, peluang kenaikan pangkat, penyeliaan, hubungan dengan rakan sekerja, faedah sampingan dan kepuasan kerja keseluruhan. Sepuluh (10) ciri-ciri demografi terpilih telah dikaji untuk menentukan sama ada wujud atau tidak perkaitannya dengan kepuasan dan 
prestasi kerja. Elemen-elemen prestasi kerja seperti kehadiran, ketepatan waktu kerja, disiplin kerja, kualiti dan kuantiti produk, kesanggupan melakukan kerja di luar rutin kerja serta amalan membantu dan bekerjasama dengan rakan-rakan sekerja telah dijadikan sebagai pengukuran tahap prestasi kerja. Beliau telah menggunakan instrumen "Job Descriptive Index" (Smith, Kendall \& Hullin, 1969) yang telah diubahsuai oleh Mohd. Majid Konting (1990). Dapatan kajian mendapati wujud perkaitan yang signifikan antara prestasi kerja dengan faktor gaji $(\mathrm{r}=.250 ; \mathrm{p}<0.01)$ dan prestasi kerja dengan rakan sekerja $(\mathrm{r}=.195 ; \mathrm{p}<0.05)$. Selain itu, dapatan perbezaan tahap kepuasan kerja dengan ciri-ciri demografi menunjukkan bahawa responden lelaki lebih berpuas hati terhadap penyeliaan jika dibandingkan dengan responden wanita. Responden bujang didapati lebih berpuas hati terhadap rakan sekerja dan faktor kepuasan kerja keseluruhan. Kajian juga mendapati responden sekolah rendah mempunyai tahap kepuasan yang lebih tinggi daripada responden SPM/SPVM/MCE bagi faktor gaji dan dengan responden PMR/SRP/LCE bagi faktor kenaikan pangkat. Walaubagaimanapun kajian mendapati tahap kepuasan responden sekolah rendah adalah lebih rendah daripada responden PMR/SRP/LCE bagi faktor penyeliaan. Perbezaan tahap prestasi di antara kumpulan ciri-ciri demografi mendapati tidak terdapat perbezaan yang signifikan bagi kumpulan demografi jantina, latihan berkaitan tugas dan status perkahwinan. Namun demikian, kajian mendapati wujud perbezaan yang signifikan prestasi kerja antara kumpulan bagi demografi tahap pendidikan. Secara keseluruhannya, kajian mendapati prestasi responden sekolah rendah dan PMR/SRP/LCE adalah lebih tinggi daripada responden STPM ke atas. Tambahan pula, Anuar bin Hussin (2011) telah menjalankan satu kajian untuk menentukan tahap kepuasan kerja dan prestasi kerja serta mengenalpasti hubungan di antara komponen-komponen kepuasan kerja iaitu gaji, kenaikan pangkat, kerja itu sendiri, penyeliaan dan rakan sekerja dengan prestasi kerja. Kajian ini telah dijalankan ke atas 115 responden di Kumpulan Syarikat-Syarikat Tradewinds di Lembah Klang. Dapatan kajian menunjukkan hubungan yang positif di antara komponen kepuasan kerja iaitu kenaikan pangkat, kerja itu sendiri, penyeliaan dan rakan sekerja kecuali komponen gaji terhadap prestasi kerja. Selain itu, kajian juga mendapati terdapat perbezaan yang signifikan di antara kedudukan jawatan seseorang terhadap prestasi kerja. Hasil kajian ini juga membuktikan bahawa dimensi kepuasan kerja iaitu gaji, kenaikan pangkat, kerja itu sendiri, penyeliaan dan rakan sekerja boleh menyumbang sebanyak 17.8 peratus (\%) bagi meningkatkan prestasi kerja dalam organisasi tersebut.

Di samping itu, Aznira Zakaria (2014) telah menjalankan kajian di Kompleks Kastam Bukit Kayu Hitam, Kedah yang terdiri daripada 80 orang ejen penghantaran yang bertugas di organisasi tersebut yang mewakili hampir 38 buah syarikat logistik di sekitarnya. Kajian tersebut bertujuan untuk menilai tahap kepuasan kerja dan prestasi kerja dalam kalangan responden, menilai perhubungan di antara dimensi-dimensi kepuasan kerja dengan prestasi kerja serta mengenalpasti dimensi-dimensi penting yang mempengaruhi tahap kepuasan kerja responden. Beliau telah mengumpul data melalui borang soal selidik berasaskan instrumen "Job Descriptive Index". Hasil kajian menunjukkan bahawa tidak terdapat perbezaan antara prestasi kerja berdasarkan faktor demografi. Selain itu, dapatan kajian mendapati hubungan yang signifikan di antara dimensi-dimensi kepuasan kerja iaitu kerja itu sendiri $(\mathrm{r}=.523, \mathrm{p}<0.01)$, gaji $(\mathrm{r}=.396, \mathrm{p}<0.01)$, penyelia $(\mathrm{r}=.517, \mathrm{p}<0.01)$ dan rakan sekerja $(\mathrm{r}=.489, \mathrm{p}<0.01)$ terhadap prestasi kerja. Hasil kajian juga mendapati bahawa kepuasan kerja mempengaruhi prestasi kerja sebanyak 47.1 peratus (\%). Kesimpulannya, dapatan kajian mendapati dimensi kepuasan kerja mempengaruhi prestasi kerja dalam kalangan responden yang dikaji iaitu ejen penghantaran.

\section{Kerangka Kajian}

\section{Kerangka Konseptual Kajian}

Rajah 1 menunjukkan kerangka konseptual yang digunakan dalam kajian ini. Kajian ini melihat kepada dua (2) aspek utama iaitu faktor komitmen kerja dan prestasi kerja. Kajian menumpukan faktor-faktor komitmen kerja seperti faktor penyelia, faktor minat terhadap pekerjaan, faktor rakan sekerja dan faktor pendapatan. Faktor demografi juga turut diambil kira dimana maklumat responden seperti jantina, umur dan tempoh perkhidmatan diperlukan untuk dijadikan sebagai pembolehubah terdahulu seterusnya mengkaji perbezaan prestasi kerja ini mengikut faktor demografi yang diperoleh. Seterusnya, dari aspek prestasi kerja, kajian akan mengukur prestasi seseorang pekerja dari aspek 
kepimpinan dan kualiti peribadi iaitu dengan menggunakan indikator seperti kebolehan menguruskan sumber, jalinan hubungan dan kerjasama, keberkesanan komunikasi, disiplin kerja, komitmen terhadap pekerjaan, kualiti dan kuantiti produk dan orientasi pencapaian yang diperoleh. Ringkasnya, kajian ini ingin melihat perkaitan di antara pembolehubah bebas, iaitu faktor komitmen kerja yang terdiri daripada empat faktor terhadap pembolehubah bersandar, iaitu prestasi kerja. Di samping itu, ciri-ciri demografi seperti jantina, umur dan tempoh perkhidmatan juga diambil kira untuk melihat perbezaan prestasi kerja dalam kalangan pekerja disesuatu organisasi.

\section{Definisi Konseptual \& Operasional Kajian}

\section{Komitmen Kerja}

Definisi Konseptual: Mottaz (1988) menyatakan komitmen ialah sebagai hasil tindak balas afektif daripada penilaian individu terhadap kerjanya yang mungkin boleh mengikat individu dengan institusi atau organisasi. Menurut Mottaz lagi, individu menyertai organisasi untuk membolehkannya menggunakan kemahiran, memenuhi keinginan dan mencapai matlamat individu. Sekiranya organisasi tidak dapat memberikan peluang untuk individu itu, peluang untuk mencapai kehendak dan matlamat, maka komitmen individu akan lenyap.

Definisi Operasional: Dalam konteks kajian ini, komitmen kerja dilihat sebagai usaha, kerja keras dan kesukarelaan pekerja untuk menyumbang kepada matlamat organisasi. Bennet dan Durkin (2000) menyatakan bahawa kepuasan kognitif terhadap perhubungan kerja, sekaligus kesetiaan seseorang pekerja itu terhadap organisasi akan menjelmakan komitmen. Oleh itu, kajian ini memfokuskan kepada empat faktor yang mempengaruhi komitmen seseorang pekerja iaitu penyelia, minat, rakan sekerja dan pendapatan. Penyelidik menggunakan instrumen yang diterbitkan oleh Bowling Green State University (2009) iaitu "Job Descrpitive Index 2009 Revision" bagi mengukur faktor-faktor tersebut.

Pembolehubah Terdahulu

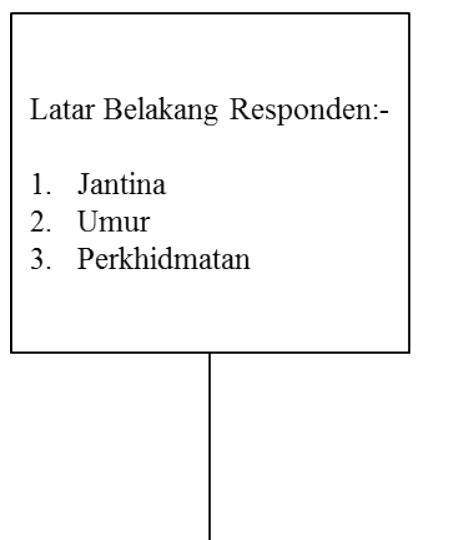

Pembolehubah Bebas/ Tidak Bersandar

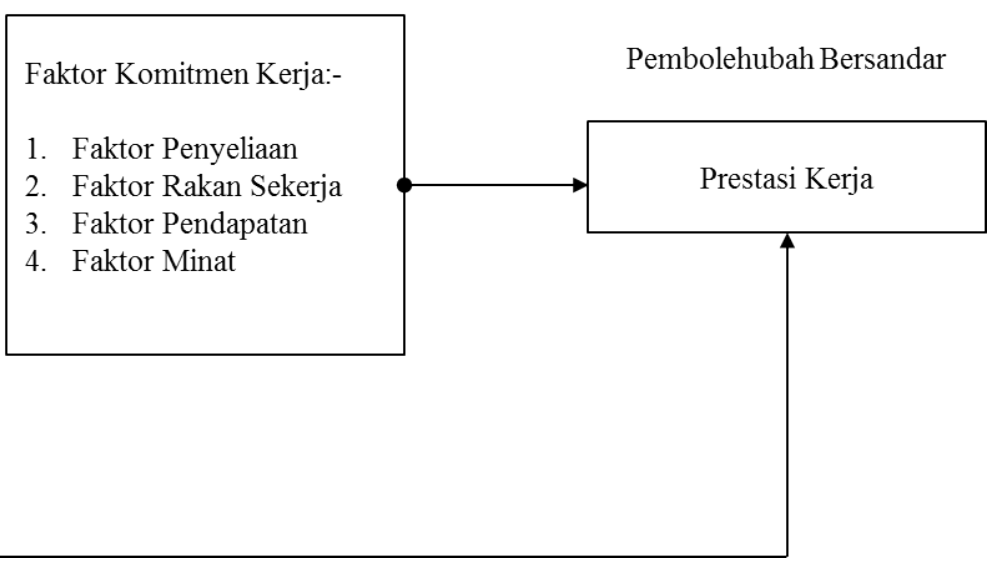

Rajah 1: Kerangka konseptual Faktor Komitmen Kerja kepada Presatsi Kerja

\section{Prestasi Kerja}

Definisi Konseptual: Prestasi kerja merujuk kepada tingkah laku atau sikap yang menunjukkan seseorang itu berhubungan dengan pekerjaannya dan kebiasannya merujuk kepada tindakan dan tingkah laku di bawah kawalan seseorang individu yang menyumbang kepada matlamat organisasi (Rotundo dan Sackett, 2002). 
Definisi Operasional: Dalam konteks kajian ini, prestasi kerja merujuk kepada hasil kerja yang telah dicapai oleh seseorang dalam melaksanakan tugas-tugas yang dibebankan kepadanya. Prestasi kerja penjawat awam diukur berdasarkan kepada aspek-aspek seperti kebolehan menguruskan sumber, jalinan hubungan dan kerjasama, keberkesanan komunikasi, disiplin kerja, komitmen terhadap pekerjaan, kualiti dan kuantiti produk dan orientasi pencapaian. Penyelidik telah menggunakan borang soal selidik yang diadaptasi daripada Aznira Binti Zakaria (2014) untuk mengukur prestasi kerja berdasarkan aspek-aspek tersebut.

\section{Kaedah Kajian}

\section{Rekabentuk Kajian}

Rekabentuk kajian yang digunakan oleh penyelidik adalah kajian deskriptif berbentuk tinjauan bagi mengenalpasti dan mengkaji secara empirikal dan sistematik berkaitan dengan faktor komitmen kerja terhadap prestasi kerja. Kajian ini bersifat kuantitatif dan menggunakan borang soal selidik bagi memperoleh data daripada responden. Penyelidikan kuantitatif boleh dirujuk sebagai kajian yang menggunakan statistik yang melibatkan bilangan responden yang ramai dengan sekurang-kurangnya melebihi 10 sampel dalam mengukur pembolehubah bagi sesuatu penyelidikan tersebut (Krejcie \& Morgan, 1970). Kajian penyelidikan yang menggunakan kaedah kuantitatif dilakukan melalui kajian eksperimental dan data numerika yang diperoleh dan dianalisis dengan ujian statistik (Chua, 2011). Data-data ini wajib diukur bagi membuktikan kebolehpercayaan dan dapat digunakan untuk menguji teori, membina fakta dan menyatakan kewujudan perhubungan antara pembolehubah-pembolehubah.

\section{Pembolehubah}

Terdapat tiga pembolehubah didalam kajian ini iaitu i) pembolehubah terdahulu, ii) pembolehubah bebasa atau tidak bersandar, dan iii) pembolehubah bersandar. Pembolehubah terdahulu adalah maklumat latar belakang responden seperti jantina, umur dan tempoh perkhidmatan. Pembolehubah tidak bersandar yang akan diukur adalah faktor komitmen kerja yang merangkumi i) faktor penyeliaan, ii) faktor rakan sebaya, iii) faktor pendapatan dan iv) faktor minat manakala pembolehubah yang bersandar adalah prestasi kerja.

\section{Persampelan kajian}

Penentuan saiz sampel dalam kajian ini adalah berasaskan kepada persampelan rawak mudah. Ia dilakukan dengan menggunakan kaedah memilih sampel daripada populasi dari senarai yang banyak dengan menggunakan jadual nombor rawak. Dalam pemilihan saiz sampel bagi kajian ini, penyelidik telah berpandukan kepada jadual penentuan saiz sampel berasaskan Krejcie dan Morgan (1970) seperti yang ditunjukkan dalam Jadual 1: Jadual Penentuan Saiz Sampel berasaskan Krejcie \& Morgan (1970).

Jadual 1: Jadual Penentuan Saiz Sampel Berasaskan Krejcie \& Morgan (1970)

\begin{tabular}{cccccc}
\hline $\begin{array}{c}\text { Populasi } \\
(\mathrm{N})\end{array}$ & $\begin{array}{c}\text { Sampel } \\
(\mathrm{n})\end{array}$ & $\begin{array}{c}\text { Populasi } \\
(\mathrm{N})\end{array}$ & $\begin{array}{c}\text { Sampel } \\
(\mathrm{n})\end{array}$ & $\begin{array}{c}\text { Populasi } \\
(\mathrm{N})\end{array}$ & $\begin{array}{c}\text { Sampel } \\
(\mathrm{n})\end{array}$ \\
\hline 90 & 73 & 460 & 210 & 4500 & 354 \\
95 & 76 & 480 & 214 & 5000 & 357 \\
100 & 80 & 500 & 217 & 6000 & 361 \\
110 & 86 & 550 & 226 & 7000 & 364 \\
120 & 92 & 600 & 234 & 8000 & 367 \\
130 & 97 & 650 & 242 & 9000 & 368 \\
140 & 103 & 700 & 248 & 10000 & 370 \\
150 & 108 & 750 & 254 & 15000 & 375 \\
160 & 113 & 800 & 260 & 20000 & 377 \\
170 & 118 & 850 & 265 & 30000 & 379 \\
180 & 123 & 900 & 269 & 40000 & 380 \\
\hline
\end{tabular}




\begin{tabular}{cccccc}
\hline 190 & 127 & 950 & 274 & 50000 & 381 \\
200 & 132 & 1000 & 278 & 75000 & 382 \\
210 & 136 & 1100 & 285 & 100000 & 384 \\
\hline
\end{tabular}

\section{Intrsumen Kajian}

Terdapat tiga bahagian di dalam set borang soal selidik iaitu Bahagian A, B dan C. Bahagian A mengandungi soalan-soalan berkaitan dengan maklumat responden seperti jantina, umur dan tempoh perkhidmatan. Seterusnya Bahagian B mengandungi soalan-soalan berkaitan dengan faktor-faktor komitmen kerja iaitu faktor penyelia, faktor rakan sekerja, faktor pendapatan dan faktor minat. Akhir sekali Bahagian $\mathrm{C}$ mengandungi soalan-soalan berkaitan dengan prestasi kerja.

Jadual 2: Kandungan Borang Soal Selidik

\begin{tabular}{clcc}
\hline Bahagian & \multicolumn{1}{c}{ Item } & Bilangan Item & Pembolehubah \\
\hline \multirow{2}{*}{ A } & Jantina & 1 & Terdahulu \\
& Umur & 1 & \\
& Tempoh perkhidmatan & 1 & \\
& Faktor Penyelia & 18 & Bebas \\
B & Faktor Minat & 18 & \\
& Faktor Rakan Sekerja & 18 & Bersandar \\
& Faktor Pendapatan & 9 & \\
\hline
\end{tabular}

Bahagian B: Komitmen Kerja diadaptasi daripada borang soal selidik yang telah diterbitkan oleh Bowling Green State University (2009) iaitu "Job Descriptive Index 2009 Revision". Soal selidik bagi bahagian ini mengandungi 63 item soalan berkaitan dengan faktor-faktor komitmen kerja yang merangkumi empat faktor iaitu faktor penyelia, faktor minat, faktor rakan sekerja dan faktor pendapatan. Setiap kategori faktor ini mengandungi bilangan soalan yang berbeza dan soalan yang dikemukakan telah disusun secara rawak. Soal selidik asal yang diadaptasi oleh pengkaji adalah berbahasa inggeris. Oleh itu, soalan-soalan yang dipilih pengkaji telah diubahsuai, diolah dan disesuaikan dalam bahasa melayu mengikut objektif dan kehendak kajian seperti yang ditunjukkan dalam jadual-jadual di bawah. Soalan-soalan yang diolah adalah berbentuk pernyataan yang positif dan kebanyakannya berbentuk "close-ended". Pembentukan pernyataan sebegini memberi maklumat yang lebih khusus dan memudahkan responden bagi membuat pilihan jawapan.

Jadual 3: Butiran Pengolahan Pernyataan bagi Faktor Penyelia

\begin{tabular}{lll}
\hline & \multicolumn{1}{c}{ Pernyataan Asal } & \multicolumn{1}{c}{ Pengolahan Pernyataan } \\
\hline 1. & Supportive & Penyelia saya sentiasa menyokong saya dalam pekerjaan \\
2. & Hard to please & Penyelia saya seorang yang tegas \\
3. & Impolite & Penyelia saya berkelakuan tidak sopan \\
4. & Praises good work & Penyelia saya sentiasa memuji hasil kerja saya yang baik \\
5. & Tactful & Penyelia saya sentiasa berhati-hati dalam pertuturannya \\
6. & Influential & Penyelia saya seorang yang berpengaruh \\
7. & Up-to-date & Penyelia saya sentiasa mengikuti perkembangan semasa \\
8. & Unkind & Penyelia saya seorang yang tidak baik \\
9. & Has favorites & Penyelia saya mempunyai pekerja yang diminatinya \\
10. & Tells me where I stand & Penyelia saya sentiasa menerangkan di mana kedudukan \\
11. & Annoying & saya semasa menjalankan tugas \\
12. & Stubborn & Penyelia saya seorang yang menjengkelkan \\
13. & Knows job well & Penyelia saya amat degil \\
\hline
\end{tabular}




\begin{tabular}{lll}
\hline 14. & Bad & Penyelia saya bukan orang yang baik \\
15. & Intelligent & Penyelia saya seorang yang bijak \\
16. & Poor planner & Penyelia saya tidak mahir dalam merancang \\
17. & Around when needed & Penyelia saya sentiasa ada apabila diperlukan \\
18. & Lazy & Penyelia saya seorang yang pemalas \\
\hline
\end{tabular}

Jadual 4: Butiran Pengolahan Pernyataan bagi Faktor Minat

\begin{tabular}{|c|c|c|}
\hline & Pernyataan Asal & Pengolahan Pernyataan \\
\hline 1. & Fascinating & Kerja yang saya lakukan mempesonakan saya \\
\hline 2. & Routine & Saya membuat kerja yang rutin \\
\hline 3. & Satisfying & Saya berpuas hati dengan pekerjaan saya \\
\hline 4. & Boring & Kerja yang saya lakukan amat membosankan \\
\hline 5. & Good & Saya melakukan kerja yang baik \\
\hline 6. & $\begin{array}{l}\text { Gives sense of } \\
\text { accomplishment }\end{array}$ & $\begin{array}{l}\text { Kerja yang saya lakukan memberi pencapaian kepada } \\
\text { saya }\end{array}$ \\
\hline 7. & Respected & Pekerjaan saya amat dihormati \\
\hline 8. & Exciting & Kerja yang saya lakukan sekarang menyeronokkan \\
\hline 9. & Rewarding & Pekerjaan saya memberikan ganjaran \\
\hline 10 & Useful & Saya membuat kerja yang berguna \\
\hline 11. & Challenging & Kerja yang saya lakukan amat mencabar \\
\hline 12. & Simple & Kerja yang saya lakukan amat mudah \\
\hline 13. & Repetitive & Saya membuat kerja yang sama setiap hari \\
\hline 14. & Creative & Saya membuat kerja yang kreatif \\
\hline 15. & Dull & Pekerjaan saya amat membosankan \\
\hline 16. & Uninteresting & Kerja yang saya lakukan tidak menarik \\
\hline 17. & Can see results & Saya boleh melihat hasil daripada pekerjaan saya \\
\hline 18. & Uses my abilities & $\begin{array}{l}\text { Pekerjaan saya menggunakan segala kebolehan yang } \\
\text { saya punyai }\end{array}$ \\
\hline
\end{tabular}

Jadual 5: Butiran Pengolahan Pernyataan bagi Faktor Rakan Sekerja

\begin{tabular}{lll}
\hline & \multicolumn{1}{c}{ Pernyataan Asal } & \multicolumn{1}{c}{ Pengolahan Pernyataan } \\
\hline 1. & Stimulating & Rakan sekerja saya amat merangsangkan saya \\
2. & Boring & Rakan sekerja saya membosankan \\
3. & Slow & Rakan sekerja saya lembab \\
4. & Helpful & Rakan sekerja sering membantu saya dalam melaksanakan \\
5. & Stupid & Rakan sekerja saya bodoh \\
6. & Responsible & Rakan sekerja saya seorang yang bertanggungjawab \\
7. & Likeable & Saya suka dengan rakan sekerja saya \\
8. & Intelligent & Rakan sekerja saya seorang yang bijak \\
9. & Easy to make enemies & Rakan sekerja saya mengamalkan sikap bermusuhan \\
10. & Rude & Rakan sekerja saya kurang ajar \\
11. & Smart & Rakan sekerja saya seorang yang pintar \\
12. & Lazy & Rakan sekerja saya seorang yang pemalas dan suka \\
13. & Unpleasant & menangguhkan kerjanya \\
14. & Supportive & Rakan sekerja saya tidak disenangi \\
15. & Active & Rakan sekerja saya sentiasa mendorong saya dalam \\
16. & Narrow interests & menyelesaikan tugasan yang diberikan \\
17. & Frustrating & Rakan sekerja saya seorang yang bergiat aktif \\
18. & Stubborn & Rakan sekerja saya mempunyai pemikiran yang sempit \\
\hline
\end{tabular}


Jadual 6: Butiran Pengolahan Pernyataan bagi Faktor Pendapatan

\begin{tabular}{|c|c|c|}
\hline & Pernyataan Asal & Pengolahan Pernyataan \\
\hline 1. & $\begin{array}{l}\text { Income adequate for } \\
\text { normal expenses }\end{array}$ & $\begin{array}{l}\text { Pendapatan yang saya terima mencukupi untuk } \\
\text { perbelanjaan saya }\end{array}$ \\
\hline 2. & Fair & Saya mendapat bayaran yang sewajarnya \\
\hline 3. & Barely live on income & $\begin{array}{l}\text { Pendapatan yang saya terima hampir tidak cukup untuk } \\
\text { menampung hidup saya }\end{array}$ \\
\hline 4. & Bad & Pendapatan yang saya terima adalah tidak baik \\
\hline 5. & Comfortable & Saya selesa dengan gaji yang saya terima \\
\hline 6. & Less than I deserve & $\begin{array}{l}\text { Gaji yang saya dapat sekarang kurang daripada yang } \\
\text { sepatutnya saya terima }\end{array}$ \\
\hline 7. & Well paid & Saya memperoleh gaji yang memuaskan \\
\hline 8. & Enough to live on & $\begin{array}{l}\text { Pendapatan yang saya terima cukup untuk menyara } \\
\text { kehidupan saya }\end{array}$ \\
\hline 9. & Underpaid & Saya mendapat bayaran yang rendah \\
\hline
\end{tabular}

Jadual 7: Kedudukan Item dalam Borang Soal selidik mengikut Kategori Faktor

\begin{tabular}{lc}
\hline \multicolumn{1}{c}{ Faktor Komitmen Kerja } & Kedudukan Item \\
\hline Faktor Penyelia & $7,8,9,10,19,20,21,22,36,37,38,39,50,51,52,53,59,60$ \\
Faktor Minat & $1,2,3,4,23,24,25,32,33,34,35,44,45,46,47,61,62,63$ \\
Faktor Rakan Sekerja & $5,6,13,14,15,16,28,29,30,31,40,41,42,43,54,55,56$, \\
Faktor Pendapatan & 57 \\
\hline
\end{tabular}

Bahagian C: Prestasi Kerja diadaptasi daripada borang soal selidik oleh Aznira Binti Zakaria (2014). Soalan asal berkaitan prestasi kerja dalam soal selidik yang diadaptasi ini mengandungi 10 item sahaja. Namun, pengkaji telah menambah sebanyak dua (2) item soalan seperti butiran di bawah supaya pembolehubah bersandar iaitu prestasi kerja dapat diukur dengan lebih tepat. Oleh itu, secara keseluruhannya sebanyak 12 item soalan telah dikemukakan untuk mengukur prestasi kerja dalam kalangan responden.

\begin{tabular}{lll}
\hline Pernyataan 1 & $:$ & $\begin{array}{l}\text { Saya mendapat Anugerah Perkhidmatan Cemerlang (APC) pada tahun } \\
\text { lepas. }\end{array}$ \\
Justifikasi & $:$ & $\begin{array}{l}\text { Menurut Pekeliling Kemajuan Pentadbiran Awam Bilangan 2 Tahun } \\
\text { 2002, Anugerah Perkhidmatan Cemerlang (APC) merupakan } \\
\text { penghargaan kerajaan kepada anggota perkhidmatan awam yang telah } \\
\text { memberi perkhidmatan yang cemerlang. Perkhidmatan cemerlang } \\
\text { yang diberikan adalah bermutu tinggi atau penghasilan kerjanya } \\
\text { melebihi daripada keperluan tanggungawab biasa bagi jawatannya. }\end{array}$ \\
& $: \quad \begin{array}{l}\text { KPI kerja saya mencecah 80\% dan ke atas. } \\
\text { Berdasarkan kepada Surat Pekeliling Bilangan } 8 \text { Tahun 2011, } \\
\text { pencapaian prestasi kerja bagi markah 80\% dan ke atas menunjuknan } \\
\text { seseorang anggota perkhidmatan awam berada pada kategori } \\
\text { pencapaian prestasi yang baik dan menepati sasaran kerajaan. }\end{array}$ \\
\hline
\end{tabular}

Bagi bahagian B dan C, responden diminta untuk memilih jawapan berdasarkan kepada skala likert. Terdapat empat jenis skala likert yang digunakan seperti ditunjukkan dalam Jadual 8. Responden perlu memilih salah satu daripada jenis skala tersebut.

Jadual 8: Skala Likert bagi Bahagian B dan C

Pernyataan Ringkasan $\quad$ Skor




\begin{tabular}{ccc}
\hline Sangat Setuju & SS & 4 \\
Setuju & S & 3 \\
Tidak Setuju & TS & 2 \\
Sangat Tidak Setuju & STS & 1 \\
\hline
\end{tabular}

\section{Pengumpulan Data}

Proses pengumpulan data dilakukan untuk mendapatkan maklumat yang diperlukan bagi mencapai objektif kajian. Proses ini mengambil masa yang lama dan perlu mengikut prosedur yang telah ditetapkan dengan betul. Teknik pengumpulan data bagi kajian ini dilakukan dalam bentuk data primer dan data sekunder. Menurut Yusof (2003), data primer adalah data yang berasal daripada sumber asli yang dikumpulkan untuk menjawab persoalan kajian. Data-data ini dikumpul oleh penyelidik melalui proses eksperimental atau kajian lapangan seperti soal selidik, pemerhatian, temu bual dan sebagainya. Dalam bidang sains sosial, data-data ini dikumpulkan daripada individu, kumpulan fokus atau melalui panel pakar. Oleh itu, dalam kajian ini data primer diperoleh melalui borang soal selidik iaitu menerusi pengedaran borang soal selidik kepada responden. Manakala dalam bentuk data sekunder pula, penyelidik telah merujuk kepada data-data daripada kajian lepas dan juga laporan serta dokumen rasmi Kerajaan Malaysia dalam mendapatkan maklumat untuk menjawab persoalan kajian. Menurut Sabitha Marican (2005), data sekunder adalah data yang telah dikumpulkan oleh pengkaji lain dimana pada awalnya dikumpul untuk tujuan lain tetapi sesuai digunakan untuk menjawab persoalan kajian yang dijalankan oleh pengkaji pada masa kini.

\section{Analisis Data}

Data yang diperoleh dianalisis dengan menggunakan perisian Statistical Package for the Social Sciences (SPSS). Penggunaan perisian ini membolehkan data dianalisis dengan mudah dan cepat serta mendapatkan data yang tepat mengikut objektif kajian. Penganalisisan data dijalankan melalui dua tahap iaitu univariat (statistik deskriptif) dan bivariat (ujian korelasi Pearson, ujian $t$ dan ujian anova).

Statistik deskriptif digunakan bagi menjawab objektif yang pertama, kedua dan ketiga iaitu untuk memperihalkan latar belakang penjawat, mengenalpasti faktor komitmen kerja utama yang mempengaruhi prestasi kerja serta mengkaji tahap prestasi kerja dalam kalangan penjawat awam. Data dipersembahkan dalam bentuk nilai kekerapan (f), nilai peratusan (\%) serta nilai purata (mean). Dalam kajian ini, nilai kekerapan (f) dan peratusan (\%) digunakan untuk menganalisis latar belakang responden manakala nilai purata (mean) digunakan untuk mengenalpasti purata bagi setiap faktor komitmen kerja iaitu faktor penyelia, faktor minat, faktor rakan sekerja dan faktor pendapatan bagi menentukan faktor utama yang mempengaruhi prestasi kerja serta mengkaji tahap prestasi kerja. Selain itu, ujian korelasi Pearson pula digunakan untuk menentukan perkaitan antara dua pembolehubah iaitu pembolehubah bebas (faktor komitmen kerja) dan pembolehubah bersandar (prestasi kerja) serta menguji hipotesis-hipotesis yang dibina. Seterusnya bagi menjawab objektif kelima, ujian $t$ dan anova digunakan. Ujian $t$ digunakan untuk mengenalpasti perbezaan prestasi kerja mengikut jantina manakala ujian anova digunakan untuk mengenalpasti perbezaan prestasi kerja mengikut umur dan tempoh perkhidmatan. Jadual 9 menunjukkan kaedah analisis data secara terperinci yang digunakan untuk mencapai objektif kajian yang telah ditetapkan.

Jadual 9: Kaedah Analisis Data

\begin{tabular}{|c|c|c|}
\hline & Objektif & Analisis Data \\
\hline 1. & Untuk memperihalkan latar belakang penjawat awam. & Analisis deskriptif \\
\hline 2. & $\begin{array}{l}\text { Untuk mengenalpasti faktor komitmen kerja utama yang } \\
\text { mempengaruhi prestasi kerja dalam kalangan penjawat awam. }\end{array}$ & Analisis deskriptif \\
\hline 3. & $\begin{array}{l}\text { Untuk mengkaji tahap prestasi kerja dalam kalangan penjawat } \\
\text { awam. }\end{array}$ & Analisis deskriptif \\
\hline 4. & $\begin{array}{l}\text { Untuk mengkaji hubungan antara faktor komitmen kerja } \\
\text { dengan prestasi kerja dalam kalangan penjawat awam. }\end{array}$ & $\begin{array}{l}\text { Ujian korelasi } \\
\text { Pearson }\end{array}$ \\
\hline 5. & Untuk mengenalpasti perbezaan prestasi kerja mengikut & Ujian $t$ dan anova \\
\hline
\end{tabular}


jantina, umur dan tempoh perkhidmatan dalam kalangan

penjawat awam.

\section{Ujian Kebolehpercayaan Instrumen}

Kesahan dan tahap kebolehpercayaan instrumen yang dibina adalah baik kerana nilai cronbach's alpha melebihi $0.7(\alpha>0.7)$. Semakin tinggi nilai cronbach's alpha, semakin tinggi kebolehpercayaan instrumen yang dibina. Jadual 10 menunjukkan nilai cronbach's alpha bagi setiap instrumen.

Jadual 10: Nilai Kebolehpercayaan Instrumen

\begin{tabular}{llcc}
\hline Instrumen & Pembolehubah & Bilangan Item & Cronbach's Alpha \\
\hline & Faktor Penyelia & 18 & 0.726 \\
Job Descriptive Index 2009 & Faktor Minat & 18 & 0.752 \\
Revision & Faktor Rakan Sekerja & 18 & 0.784 \\
& Faktor Pendapatan & 9 & 0.723 \\
Borang soal selidik oleh Aznira & Prestasi Kerja & 12 & 0.856 \\
Zakaria (2014) & & & \\
\hline
\end{tabular}

\section{Limitasi Kajian}

Limitasi kajian secara praktiknya tidak dapat dielakkan. Hal ini kerana limitasi wujud setiap kali sesuatu proses kajian dijalankan. Antara limitasi yang wujud semasa melaksanakan kajian ini adalah dari aspek sasaran responden. Tambahan pula, kajian ini menggunakan borang soal selidik untuk mengumpul data dimana ianya mempunyai beberapa kelemahan. Antara kelemahannya adalah kemungkinan berlaku ketidaktelusan ketika responden menjawab setiap soalan yang dikemukakan bagi mewakili diri mereka. Responden berkemungkinan menjawab soalan tanpa mengikut gambaran sebenar dan bukan berdasarkan pendapat peribadi mereka atau apa yang benar-benar mereka lalui. Di samping itu, penggunaan borang soal selidik yang dijawab sendiri oleh responden boleh menimbulkan unsur bias dimana ianya akan mengakibatkan keputusan yang diperoleh adalah kurang jitu.

\section{Rujukan}

Annuar Hussin (2011). The Relationship between Job Satisfaction and Job Performance among Employees in Tradewinds Group of Companies. Master Thesis, Centre for Graduate Studies, Open University Malaysia.

Aznira binti Zakaria (2014). Pengaruh Kepuasan Kerja Terhadap Prestasi Kerja. Universiti Utara Malaysia, 06010 UUM Sintok, Kedah Darul Aman.

Bennett, H., and Durkin, M. (2000). The Effects of Organizational Change on Employee Psychological Attachment: An Exploratory Study. Journal of Managerial Psychology, 15 (2): 126147.

Chua, Y.P. (2011). Kaedah dan statistik penyelidikan: kaedah penyelidikan. Mcgraw-Hill Education.

Noel, T. W. (2009). The Impact of Knowledge Resource on New Venture Performance. Journal of Small Business Management, 47 (1), 1-22.

Kasran, Siti Barokah (1999) Hubungan antara sistem penilaian prestasi dan prestasi kerja di DBKU dan Telekom, Kuching. Masters thesis, Universiti Malaysia Sarawak.

Krejcie, R. V., \& Morgan, D. W. (1970). Determining sample size for research activities. Educational and psychological measurement, 30(3), 607-610.

Mohd Majid Konting (1990). "Kaedah Penyelidikan Pendidikan." Kuala Lumpur: Dewan Bahasa Dan Pustaka.

Mottaz, C. (1988). An Analysis of the relationship between attitudinal commitment and behavioral commitment. Socialogy Quarterly, 30, 143-158. 
Pekeliling Kemajuan Pentadbiran Awam, Bilangan 2. 2002. Garis panduan pemberian anugerah perkhidmatan cemerlang anggota perkhidmatan awam. Jabatan Perdana Menteri Malaysia.

Pekeliling Kemajuan Pentadbiran Awam, Bilangan 2. 2005. Garis panduan bagi mewujudkan petunjuk-petunjuk prestasi utama atau key performance indicators (KPI) dan melaksanakan pengukuran prestasi di agensi kerajaan. Jabatan Perdana Menteri Malaysia.

Pekeliling Perkhidmatan, Bilangan 4. 2002. Laporan Nilaian Prestasi Tahunan (LNPT). Jabatan Perkhidmatan Awam Malaysia.

Pekeliling Perkhidmatan, Bilangan 8. 2011. Sistem penilaian prestasi pegawai perkhidmatan awam di bawah saraan baru perkhidmatan awam (JPA.BK. (S) 174/3/2-20 (2)). Jabatan Perkhidmatan Awam Malaysia.

Perlembagaan Persekutuan, Bahagian X. Perkhidmatan-Perkhidmatan Awam. Undang-undang Malaysia.

Rambli Haji Hasbi (2001). Perkaitan Kepuasan Kerja dengan PrestasiKerja di kalangan Pekerja di Industri Pembuatan. Fakulti Sains Kognitif dan Pembangunan Manusia, Universiti Malaysia Sarawak

(UNIMAS). https://ir.unimas.my/id/eprint/3758/1/Perkaitan\%20kepuasan\%20kerja\%20dengan\%20prestasi\%2 0kerja\%20di\%20kalangan\%20pekerja\%20di\%20industri\%20pembuatan.pdf

Rotundo, M., \& Sackett, P. R. (2002). The relative importance of task, citizenship, and counterproductive performance to global ratings of job performance: a policy-capturing approach. The Journal of Applied Psychology, 87(1), 66-80.

Sabitha Marican. (2005). Kaedah Penyelidikan Sains Sosial. Petaling Jaya, Selangor: Pearson Prentice Hall.

Smith, P.C., L.M. Kendall, and C.L. Hulin (1969). The Measurement of Satisfaction in Work and Retirement. Chicago: Rand McNally.

Yusof, R (2003). Penyelidikan Sains Sosial (Social Science Research). Pahang, Malaysia. PTS Publications \& Distributors (Malay Version). 